\title{
RANCANG BANGUN ALAT PEMANTAUAN PENGATURAN KECEPATAN PUTAR MOTOR DC POWER WINDOWS BERBASIS PLC PANASONIC MENGGUNAKAN HUMAN MACHINE INTERFACE (HMI)
}

\author{
Agustin Anarwati, Iman Setiono \\ Program Studi Diploma III Teknik Elektro \\ Sekolah Vokasi Universitas Diponegoro
}

\begin{abstract}
Agustin Anarwati, Iman Setiono, today human life is very rapidly developing, one of them in the field of technology as time advances. This requires the creation of ideas to make a variety of equipment that is more practical and more reliable in meeting needs. In the industrial world today, most equipment uses PLC as a controller for various existing equipment, while the Human Machine Interface (HMI) is used to simplify monitoring existing equipment. In the automotive world, the power windows system is part of the body's electrical circuit which aims to make it easier for motorists to operate car windows. The driver can adjust the work of the power windows through a switch. When the driver presses the switch then the motor power window will rotate and will make the window work both open and close. The type of motor used in the power window system is a DC motor. One of the features of this DC motor is its speed can be controlled easily. In this case, I tried to make the design of the monitoring device setting the DC power speed of the windows power using PLC and HMI as monitors and controllers for operating the DC power windows rotating speed to make it easier, the speed can be adjusted through the output voltage from the PLC to the driver, starting from $O V D C$ up to 5 VDC. if the voltage is 5 VDC then the motor will rotate with a maximum speed of 100\%, whereas if given a 2.5 VDC input, the motor speed will be half of the 5 VDC rotational speed.
\end{abstract}

Keywords: Panasonic PLC, Human Machine Interface (HMI), Dc Power Motor Windows, PWM Driver

\section{PENDAHULUAN}

\section{Latar Belakang}

Kemajuan teknologi pada saat ini semakin berkembang dan sangat memungkinkan manusia untuk membuat alat yang bekerja secara otomatis dan dapat membantu mempermudah pekerjaan sehari-hari. Dalam dunia industri, motor arus searah banyak digunakan sebagai motor penggerak. Pemilihan motor arus searah sebagai motor penggerak karena motor arus searah memiliki rentang pengaturan kecepatan yang lebar. Pada motor arus searah (motor DC) energi listrik yang diubah adalah energi arus searah yang berasal dari sumber tegangan listrik arus searah.

Alat ini di rancang untuk mempermudah manusia dalam mengatur kecepatan putar motor dc sesuai dengan kebutuhan. Pengaturan kecepatan dilakukan dengan cara mengatur tegangan output dari PLC ke driver yaitu mulai dari 0 VDC sampai dengan 5 VDC. jika tegangan tersebut 5 VDC maka motor akan berputar dengan kecepatan maksimal $100 \%$, sedangkan apabila diberi masukan 2,5 VDC maka kecepatan motor akan setengah nya dari kecepatan putar 5 VDC. Kemudian proses pemantauan kecepatan putar motor DC menggunakan HMI. Peralatan ini disambungkan dengan PLC dengan masukan daya sebesar $24 \mathrm{Vdc}$. Kemudian dihubungkan ke motor arus searah Power Windows yang ingin kita pantau, apabila terjadi gangguan atau kerusakan kita dapat menanganinya dengan cepat sehingga kerusakan tidak menyebar ke sistem yang lain.

\section{Pembatasan Masalah}

Yang menjadi batasan masalah antara lain sebagai berikut:

- Rangkaian power supply dengan tegangan keluaran 12-24 VDC yang digunakan sebagai sumber energi motor DC power windows dan PLC.

- Tegangan keluaran PLC yang terhubung dengan driver motor diatur 1-5 VDC untuk mengatur kecepatan putar motor DC power windows, mengatur tegangan keluaran PLC merupakan bagian utama pada rancangan alat ini.

- jika tegangan tersebut 5 VDC maka motor akan berputar dengan kecepatan maksimal 100\%, sedangkan apabila diberi masukan 2,5 VDC maka kecepatan motor akan setengah nya dari kecepatan putar 5 VDC.

- Pengaturan kecepatan motor DC power windows ini kemudian dipantau menggunakan Human Machine Interface (HMI)

\begin{abstract}
Adaptor
Adaptor adalah sebuah perangkat berupa rangkaian elektronika untuk mengubah tegangan listrik yang besar menjadi tegangan listrik lebih kecil. Rangkaian inti dari adaptor/ power supply adalah suatu rangkaian penyearah yaitu rangkaian untuk mengubah arus bolak-balik (arus AC) menjadi arus searah (arus DC). Rangkaian ini adalah alternatif pengganti dari sumber tegangan DC, misalnya batu baterai atau akumulator. Keuntungan dari adaptor di bandingkan batu baterai atau akumulator adalah sangat praktis berhubungan
\end{abstract}


dengan ketersediaan tegangan karena adaptor dapat mengambil sumber tegangan AC yang ada dirumah, dimana pada zaman sekarang ini setiap rumah sudah menggunakan listrik. Selain itu adaptor memiliki jangka waktu yang tidak terbatas asal ada tegangan $\mathrm{AC}$, tegangan $\mathrm{AC}$ ini sudah merupakan kebutuhan primer dalam kehidupan manusia.

- Adaptor yang kita kenal kebanyakan yaitu mengubah dari listrik PLN 220 Volt (arus AC) menjadi tegangan listrik lebih kecil (arus DC) yaitu menjadi 5 volt DC, 12 volt DC, 19 volt DC, 24 volt DC dan sebagainya tergantung keperluan perangkat apa yang digunakan.

- Ada juga adaptor yang mengubah dari listrik PLN 220 Volt AC menjadi tegangan listrik lebih kecil namun arusnya tetap AC, misalnya menjadi 9 volt AC, atau 24 Volt AC. Adaptor disebut juga charger ditunjukkan oleh gambar 1 .

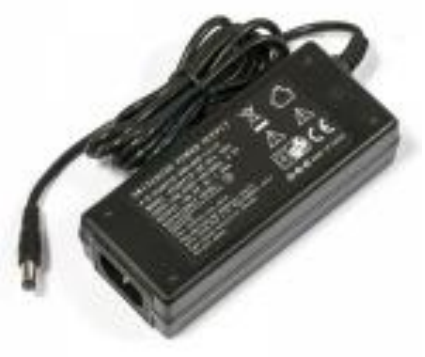

Gambar 1. Adaptor

\section{Programmable Logic Controllers (PLC)}

Programmable Logic Controllers (PLC) adalah komputer elektronik yang mudah digunakan (user friendly) yang memiliki fungsi kendali untuk berbagai tipe dan tingkat kesulitan yang beraneka ragam. Definisi Programmable Logic Controller menurut Capiel (1982) adalah sistem elektronik yang beroperasi secara dijital dan didisain untuk pemakaian di lingkungan industri, dimana sistem ini menggunakan memori yang dapat diprogram untuk penyimpanan secara internal instruksi-instruksi yang mengimplementasikan fungsi-fungsi spesifik seperti logika, urutan, perwaktuan, pencacahan dan operasi aritmatik untuk mengontrol mesin atau proses melalui modul-modul I/O digital maupun analog. Blok diagram PLC ditunjukkan oleh gambar 2.

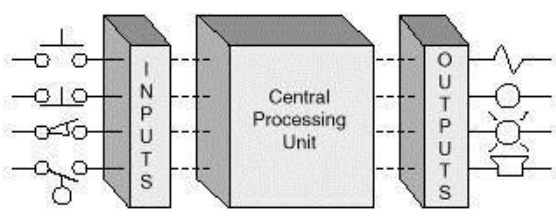

Gambar 2. Blok diagram PLC

\section{Driver Motor DC}

Metode dalam pengaturan kecepatan putaran motor DC salah satunya yang populer adalah dengan teknik PWM (Pulse Width Modulation). Dengan metode PWM ini motor DC diberikan sumber tegangan yang stabil dengan frekuensi kerja yang sama tetapi ton duty cycle pulsa kontrol kecepatan motor DC yang bervariasi. Konsep PWM pada driver motor DC adalah mengatur lebar sisi positif dan negatif pulsa kontrol pada frekuensi kerja yang tetap. Semakin lebar sisi pulsa positif maka semakin tinggi kecepatan putaran motor DC dan semakin lebar sisi pulsa negatif maka semakin rendah kecepatan putaran motor DC. Metode PWM pada driver motor DC secara singkat dapat dijelaskan menggunakan rangkaian driver motor DC satu arah dengan kontrol PWM menggunakan IC NE555 seperti pada gambar 3 .

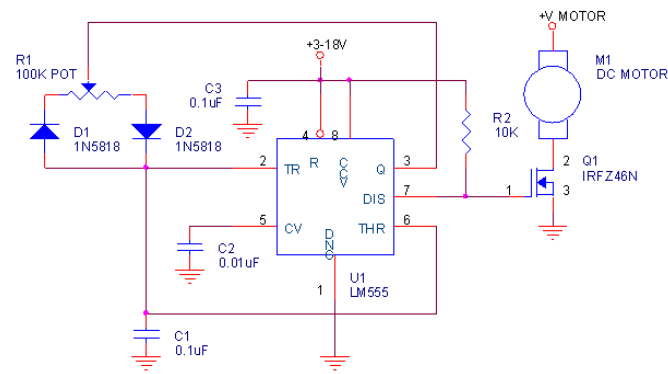

Gambar 3. Rangkaian driver motor

Rangkaian sederhana diatas dapat memberikan gambaran tentang teknik PWM pada driver motor DC. IC 555 diset sebagai astabil multivibrator dengan frekuensi kerja tetap (nilai RC tetap) dengan output diberikan ke rangkaian driver motor DC sederhana dengan MOSFET. Konsep dasar kontrol PWM menggunakan rangkaian diatas terletak pada penambahan 2 buah dioda yang mengendalikan

proses charge dan discharge kapasitor $\quad \mathrm{C} \quad 0,1 \mathrm{uF}$. Posisi tuas potensiometer $100 \mathrm{~K}$ yang terhubung dengan 2 buah dioda tersebut akan menetukan waktu charge atau discharge kapasitor $\mathrm{C} \quad 0,1 \mathrm{uF}$. Berikut bentuk gelombang charge dan discharge terhadap output astabil multivibrator NE555 sebagai kontrol PWM driver motor DC pada rangkaian sebelumnya.

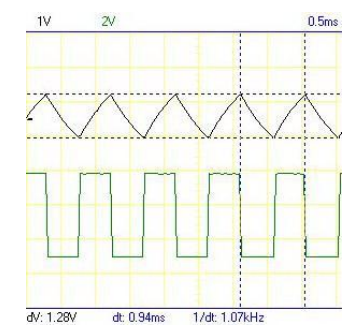

Gambar 4. Posisi tuas potensiometer ditengah (Ton Duty Cycle 50\%) 


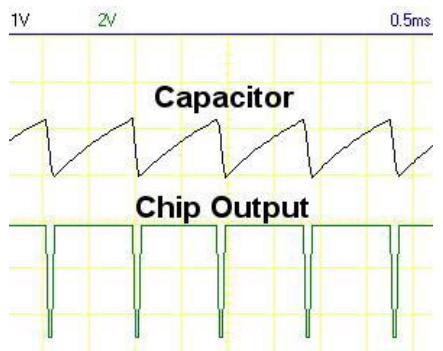

Gambar 5.Posisi tuas potensiometer pada sudut D1 (Ton Duty Cycle $\pm 95 \%$ )

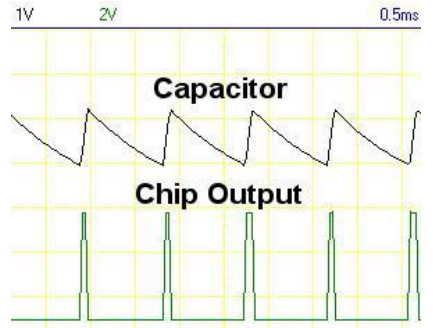

Gambar 6. Posisi Tuas Potensiometer Pada Sudut D2 (Ton Duty Cycle $\pm 5 \%$ )

Dengan tiga posisi tuas potensiometer seperti ditunjukkan oleh gambar 4-5, bentuk pulsa output yang dihasilkan oleh astabil multivibrator bervariasi dengan ton duty cyle 50\%, 90\% dan 5\% dimana semakin tingi ton duty cycle-nya maka daya yang di berikan ke motor DC semakin besar dan kecepatan motor DC semakin tinggi begitu pula sebaliknya.

\section{Motor DC}

Motor DC atau Motor Arus Searah adalah mesin listrik yang mengubah energi listrik arus searah menjadi energi mekanik. Terdapat 2 (dua) prinsip dasar yang melatarbelakangi kerja motor DC. Yang pertama yaitu adanya aliran arus yang melewati sebuah konduktor atau penghantar.Dimana,akan timbul medan magnet mengelilingi penghantar tersebut. Arah garis gaya magnet (fluks magnet) ini sesuai kaidah tangan kiri yang ditunjukan pada gambar 7. Ibu jari menandakan arah arus elektron yang mengalir dan jari-jari menunjukan arah dari garis gaya magnet (fluks) yang mengelilingi penghantar.

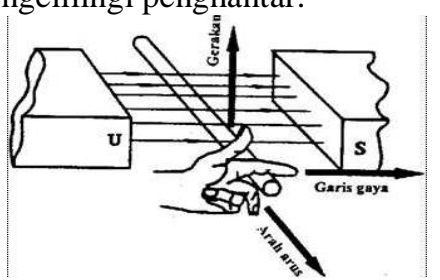

Gambar 7.Arah garis gaya magnet

Yang kedua adalah gaya pada penghantar bergerak dalam medan magnet. Besarnya gaya yang didesakkan untuk menggerakkan berubah sebanding dengan kekuatan medan magnet, besarnya arus yang mengalir pada penghantar, dan panjang penghantar.gaya tersebut sering disebut gaya Lorentz. Sesuai dengan rumus:

$\mathrm{F}=\mathrm{B} \times \mathrm{I} \times \mathrm{l}$ (Newton)

Dimana:

$\mathrm{F}=$ Gaya pada kumparan (Newton)

$\mathrm{B}=$ Kuat medan magnet (Tesla)

$\mathrm{I}=$ Arus yang mengalir (Ampere)

$1=$ Panjang kumparan (meter)

Arah dari garis gaya magnet tergantung dari arah arus yang mengalir pada kumparan dan arah dari garis-garis fluks magnet antara dua kutub. Medan magnet mengembang diantara dua kutub dari magnet permanen atau induksi elektromagnet. Ketika penghantar berarus ditempatkan diantara dua kutub magnet, maka menghasilkan pembengkokan garis gaya. Sehingga,di satu sisi memusatkan kedua medan magnet menimbulkan medan magnet yang kuat dan disisi lain berlawanan menimbulkan medan magnet yang lemah. Garis gaya magnet yang kuat cenderung lurus keluar dan menekan kearah garis gaya magnet yang lemah. Dan menyebabkan penghantar tersebut berputar berlawanan arah jarum jam.

\section{Human Machine Interface (HMI)}

Human Machine Interface atau yang biasa disebut Man Machine Interface adalah piranti lunak antarmuka antara mesin atau plant dengan operator atau pengamat. Umumnya terdiri dari komputer pusat atau beberapa komputer terpisah berfungsi untuk memonitor dan mengontrol mesin, plant atau proses di sebuah pabrik. Tujuan pemakaian HMI adalah mengumpulkan dan menampilkan informasi dari proses pada plant. Selain itu HMI berguna sebagai sarana bagi operator untuk mengakses sistem otomasi di lapangan (operasional, perawatan $\&$ troubleshooting, pengembangan).

Fitur-fitur yang terdapat dalam HMI biasanya adalah

Informasi Plant : Variabel proses, status peralatan, alarm, lup control, dan database. Metode Presentasi : Grafik, report, animasi. Peralatan : Keyboard, mouse atau pointing device lainnya, dan touchscreen atau CRT. Contoh HMI ditunjukkan oleh gambar 8 .

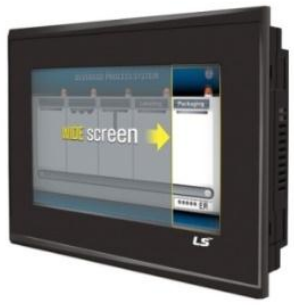

Gambar 8. LS HMI 


\section{PERANCANGAN SISTEM DAN CARA KERJA RANGKAIAN} gambar 9

Blok Diagram Rangkaian ditunjukkan oleh

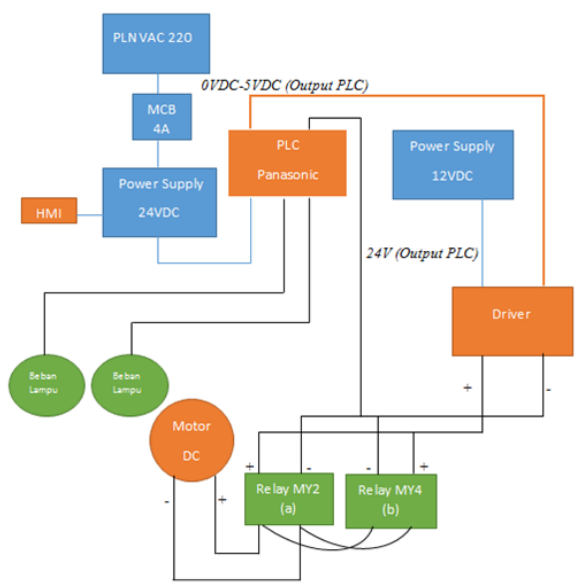

Gambar 9. Blok Diagram Keseluruhan

\section{Rangkaian Catu Daya}

Dalam rancang bangun alat ini menggunakan dua buah power supply sebagai masukannya. Sedangkan masukan dari power supply berasal dari tegangan PLN 220 AC yang kemudian masuk ke power supply dan di proses sehingga menjadi tegangan DC 24 volt dan tegangan DC 12 volt. Dijelaskan bahwasanya dalam power supply terdapat beberapa komponen seperi transformator, rectifer,filter, dan lain sebagainya. Sehingga prosesnya ketika tegangan PLN masuk 220 $\mathrm{AC}$, tegangan tersebut akan melewati tranformator step down untuk diturunkn tegangannya setelah itu masuk ke penyearah 4 gelombang yang disini tegangan AC akan di ubah menjadi tegangan DC. Kemudian melewati filter dan terakhir masuk ke dalam voltage regulator agar tegangannya menjadi stabil, sehingga tegangan keluarannya tidak berubah ubah. Power supply ini akan memberi masukan tegangan ke PLC 24 VDC, HMI 24 VDC dan motor DC power windows 12 VDC. Rangkaian catu daya ditunjukkan oleh gambar 10.

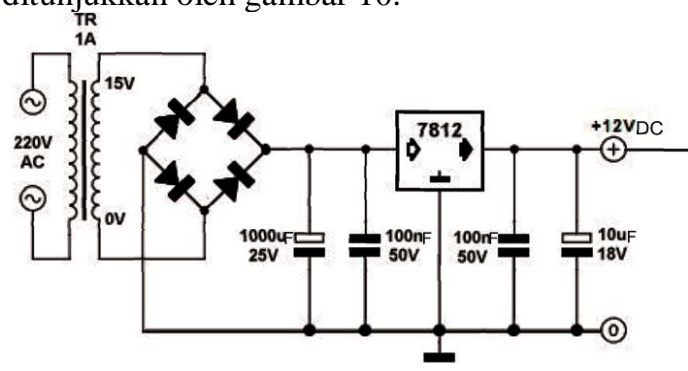

Gambar 10. Rangkaian power supply

\section{Driver Motor DC}

Metode dalam pengaturan kecepatan putaran motor DC salah satunya yang populer adalah dengan teknik PWM (Pulse Width Modulation). Dengan metode PWM ini motor DC diberikan sumber tegangan yang stabil dengan frekuensi kerja yang sama tetapi ton duty cycle pulsa kontrol kecepatan motor DC yang bervariasi. Konsep PWM pada driver motor DC adalah mengatur lebar sisi positif dan negatif pulsa kontrol pada frekuensi kerja yang tetap. Semakin lebar sisi pulsa positif maka semakin tinggi kecepatan putaran motor DC dan semakin lebar sisi pulsa negatif maka semakin rendah kecepatan putaran motor DC. Metode PWM pada driver motor DC secara singkat dapat dijelaskan menggunakan rangkaian driver motor DC satu arah dengan kontrol PWM menggunakan IC NE555 seperti pada gambar 11 .

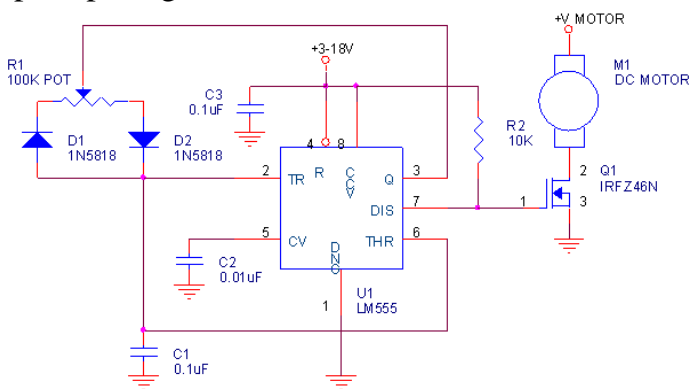

Gambar 11.Rangkaian driver motor

\section{Motor DC power windows}

Motor listrik menggunakan energi listrik dan energi magnet untuk menghasilkan energi mekanis. Operasi motor tergantung pada interaksi dua medan magnet. Secara sederhana dikatakan bahwa motor listrik bekerja dengan prinsip bahwa dua medan magnet dapat dibuat berinteraksi untuk menghasilkan gerakan. Tujuan motor adalah untuk menghasilkan gaya yang menggerakkan (torsi). Jenis motor yang digunakan pada sistem power window adalah motor DC. Salah satu keistimewaan motor DC ini adalah kecepatannya dapat dikontrol dengan mudah Dalam rancang bangun ini motor DC power windows mendapatkan inputan sebesar 12 volt DC yang berasal dari power supply 12 volt. Sehingga motor power windows dapat digerakkan, outputan motor DC power windows sendiri sebesar $0-5$ volt DC dengan Rpm maksimal 95. Sedangkan pengontrolan motor DC power windows sendiri menggunakan PLC. Contoh motor dc ditunjukkan oleh gambar 12 .

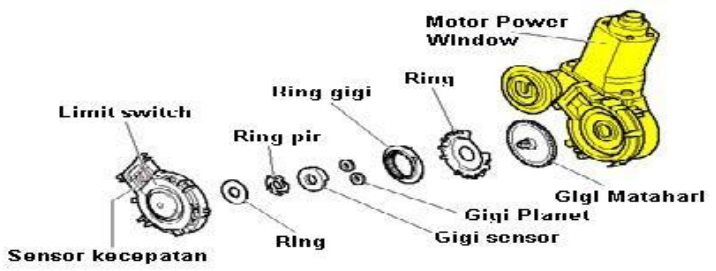

Gambar 12. Motor DC power windows 


\section{Programmable Logic Controllers}

Pada rancang bangun alat pemantau arah putaran motor DC ini menggunakan PLC panasonic sebagai kontrol utama rancang bangun alat ini, masukan dari PLC sebesar 24 volt DC dari supply adaptor 24 volt. Outputan dari PLC berasal dari V0 dan com yang kemudian akan masuk ke driver motor 0-5 volt dan ground. Program PLC menggunakan program FPWIN GR sebagai program utama untuk membuat perintah sehingga PLC dapat berjalan sebagai mana yang kita inginkan. Untuk membuat sebuah program di perlukan Flowchart agar perintah dan logika yang kita buat sesuai dengan yang kita harapkan nantinya. Flowchat program dapat dilihat pada gambar 13:

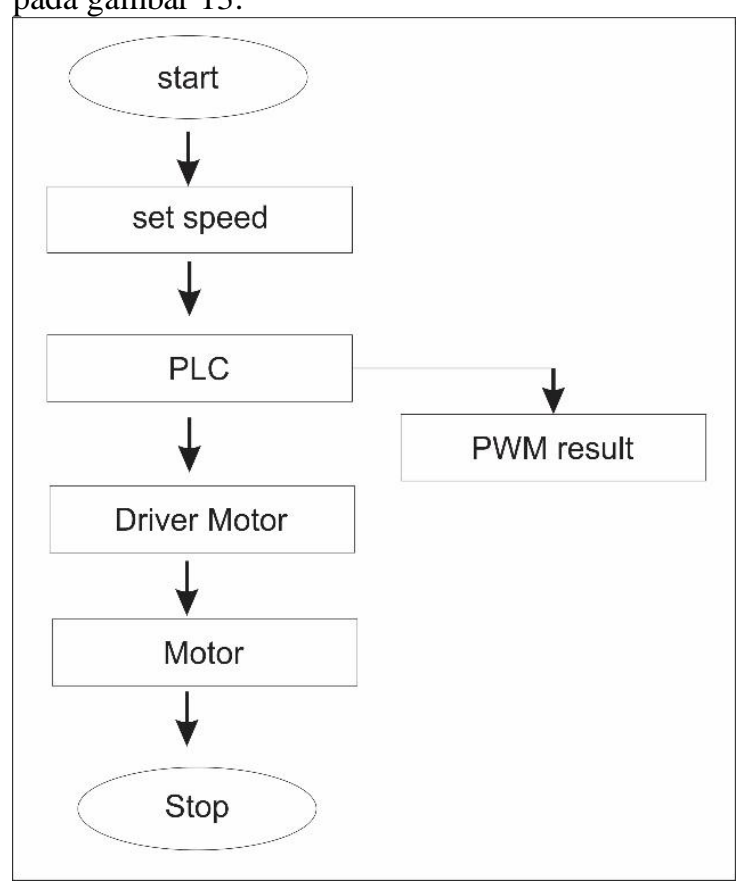

Gambar 13. Flowchart

\section{Cara Kerja Rangkaian Keseluruhan}

Pada rancang bangun alat ini tegangan input berasal dari PLN sebesar 220 VAC, kemudian tegangan tersebut dijadikan sebagai input tegangan untuk adaptor 24 VDC dan 12 VDC. Adaptor mengubah tegangan AC menjadi DC, kemudian adaptor 24 VDC masuk sebagai tegangan masuk Programmable Logic Controller (PLC). keluaran dari PLC akan masuk ke driver motor, output tersebut bisa di atur tegangannya mulai dari $0-5 \mathrm{~V}$ dengan rentang $10-100 \%$. keluaran dari driver akan masuk ke relay MY4. Cara pengaturan kecepatan putaran motor DC power windows dengan cara mengatur tegangan masuk pada driver $10-100 \%$ yaitu 1-5 VDC. Apabila di set 50\% atau sama dengan 2,5 VDC maka kecepatan putar motor Dc akan berputar setengah dari kecepatan putar maksimalnya. Sedangkan apabila di set $100 \%$ atau sama dengan 5VDC maka motor akan berputar maksimum. Motor akan bergerak atau berputar jika minimum di set $10 \%$, namun putarannya masih lambat. Program utama PLC panasonic menggunakan FwinGR. Outputan relay MY4 akan masuk kedalam motor DC power windows 12 volt DC. Untuk menggerakkan motor DC power windows dibutuhkan tegangan 12 volt DC yang diambil dari power supply 12 volt. Outputan dari motor DC adalah sebesar $0-5$ volt DC. Pemantauan kecepatan putaran motor DC power windows menggunakan human machine interface dengan program utama XP-Build. Pemantauan ini akan menampilkan tegangan keluaran motor sesuai dengan tegangan masukan yang di atur 10-100\% yang sudah dijelaskan. Tegangan masuk untuk human machine interface sendiri berasal dari power suplly 24 volt DC. Tegangan masuk dari HMI ini akan masuk ke power supply 24 volt DC sedangkan outputannya akan masuk ke PLC panasonic.

\section{PENGUKURAN DAN PERCOBAAN Rangkaian Catu Daya}

Pengukuran rangkaian catu daya sesuai gambar 14 pada dasarnya bertujuan untuk mengetahui tegangan keluaran dari rangkaian catu daya agar tegangan keluarannya dapat stabil sebagai catu daya pada masing-masing modul. Pada sistem ini menggunakan rangkaian catu daya dengan tegangan output sebesar 12 Volt dan 24 Volt. Titik pengukuran yang dilakukan meliputi input trafo yaitu dari tegangan jala-jala PLN, output dari trafo yaitu tegangan PLN yang telah diturunkan oleh trafo step down, keluaran dioda sebagai keluaran setelah tegangan disearahkan, output regulator, serta tegangan keluaran akhir. Hasil pengukuran catu daya ditunjukkan oleh tabel 1 dan tabel 2 .

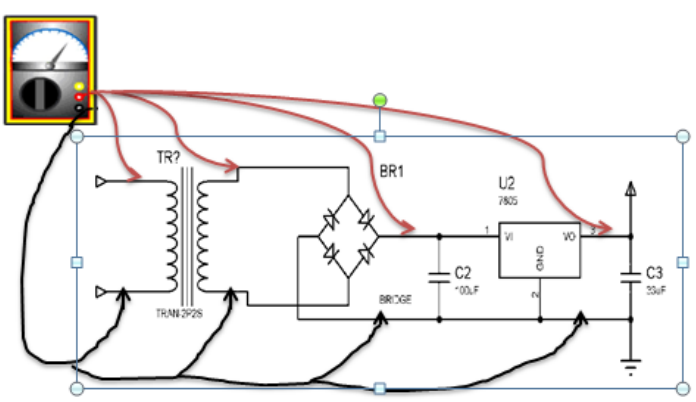

Gambar 14. Titik Pengukuran Catu Daya

Tabel 1. Hasil Pengukuran Catu Daya 12 Volt

\begin{tabular}{clc}
\hline No. & \multicolumn{1}{c}{ Bagian Yang Diukur } & Tegangan \\
\hline 1 & Tegangan Input Trafo & $226 \mathrm{~V}_{\mathrm{AC}}$ \\
2 & Tegangan Output $12 \mathrm{~V}$ & $11,8 \mathrm{~V}_{\mathrm{AC}}$ \\
3 & Tegangan Output Bridge & $15,01 \mathrm{~V}_{\mathrm{DC}}$ \\
4 & Tegangan Output Regulator & $4,99 \mathrm{~V}_{\mathrm{DC}}$ \\
\hline
\end{tabular}

Tabel 2. Hasil Pengukuran Catu Daya 24 Volt

\begin{tabular}{clc}
\hline No. & \multicolumn{1}{c}{ Bagian Yang Diukur } & Tegangan \\
\hline 1 & Tegangan Input Trafo & $226 \mathrm{~V}_{\mathrm{AC}}$ \\
2 & Tegangan Output 24 V & $23,9 \mathrm{~V}_{\mathrm{AC}}$ \\
3 & Tegangan Output Bridge & $28,01 \mathrm{~V}_{\mathrm{DC}}$ \\
4 & Tegangan Output Regulator & $7,69 \mathrm{~V}_{\mathrm{DC}}$ \\
\hline
\end{tabular}




\section{Percobaan Rangkaian Keseluruhan}

Percobaan ini dilakukan dengan cara mengoperasikan keseluruhan sistem mulai dari awal sampai akhir, meliputi hardware dan software yang digunakan dalam perancangan sistem pengaturan kecepatan putar motor DC power windows melalui tegangan inputan ke driver motor dengan skala 1-5 VDC.

Tabel 3. Hasil Pengukuran Sistem Keseluruhan

\begin{tabular}{|c|c|c|c|c|}
\hline No. & Skala & Tegangan & Arus & $\begin{array}{c}\text { Tampilan } \\
\text { HMI }\end{array}$ \\
\hline 1 & $11 \%$ & 0,81 & $0,6 \mathrm{~A}$ & 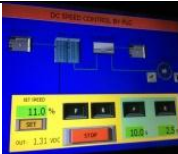 \\
\hline 2 & $25 \%$ & 2,23 & $1,7 \mathrm{~A}$ & 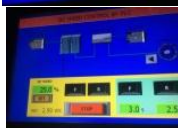 \\
\hline 3 & $50 \%$ & 5,32 & $2,3 \mathrm{~A}$ & 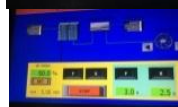 \\
\hline 4 & $75 \%$ & 8,14 & $3,5 \mathrm{~A}$ & 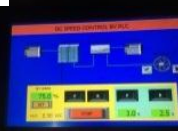 \\
\hline 5 & $100 \%$ & 10,93 & $4,8 \mathrm{~A}$ & 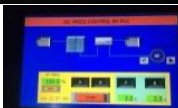 \\
\hline
\end{tabular}

Tabel 3 menunjukkan percobaan hasil percobaan pengukuran pada skala $11-100 \%$ pada motor DC power windows pada tampilan HMI menunjukkan tegangan dan skala kecepatan motor DC power windows dari 11-100 \% yang di supply dari catu daya 24 volt DC dan 12 volt DC dengan perbandingan pengukuran menggunakan multimeter didapat hasil sesuai dengan yang ada di tabel 3 .

\section{KESIMPULAN}

Kesimpulan pengujian yang telah dilakukan sebelumnya pada alat ini adalah alat tersebut dapat bekerja mangatur kecepaatan dengan men seting pada human machine interface terlebih dahulu dengan skala 11-100\% di dapat hasil yang ada di atas. Alat ini di supply dengan catu daya 12 volt untuk motor DC dan 24 volt untuk PLC dan HMI. Alat ini dapat di set otomaatis menggunakan HMI dengan cara di set dalam skala 0-60 second.

\section{DAFTAR PUSTAKA}

1. Anonim. "Sensor". 5 agustus 2015. https://id.wikipedia.org/wiki/Sensor

2. Isyanto, Jazi Eko. 2014. Pengantar Elektronika dan Instrumentasi Pendekatan Project Arduino dan Android. Yogyakarta: ANDI.

3. Koestoer, Raldi Artono.2004. Pengukuran Teknik. Jakarta: Departemen Teknik Mesin Fakultas Teknik Universitas Indonesia.
4. Massimo dkk., “Arduino/Genuino Uno”,29 juli 2015

https://www.Arduino.cc/en/Main/ArduinoBoard Uno

5. Purnama , Agus "Kapasitor" 28 juli 2015 ttp://komponenelektronika.biz/pengertiankapasitor.html

6. Riny Sulistyowati. 2012. Perancangan Prototype System Kontrol Dan Monitoring Pembatas Daya Listrik Berbasis Mikrokontroler. Surabaya : Institut Adhi Tama Surabaya.

7. Surono. 1988. Tata Tulis Karya Ilmiah Bahasa Indonesia. Semarang : Fakultas Sastra Universitas Diponegoro. 